\title{
Middle School Students Want More than Games for Health Education on the Internet
}

\author{
Henna Muzaffar ${ }^{1}$, Darla M. Castelli ${ }^{2}$, David Goss ${ }^{2}$, Jane A. Scherer ${ }^{3}$, Karen Chapman-Novakofski ${ }^{1,3}$ \\ ${ }^{1}$ Division of Nutritional Sciences, University of Illinois, Urbana-Champaign, USA; \\ ${ }^{2}$ Department of Kinesiology and Community Health, University of Illinois, Urbana-Champaign, USA; \\ ${ }^{3}$ University of Illinois Extension Service, University of Illinois, Urbana-Champaign, USA. \\ Email: kmc@illinois.edu \\ Received September 14 $4^{\text {th }}$, 2011; revised October 15 ${ }^{\text {th }}, 2011$; accepted October $28^{\text {th }}, 2011$.
}

\begin{abstract}
Our aim was to assess the views of participants in the "the HOT project: Healthy Outcomes for Teens". Twelve focus group interviews $(n=42)$ were conducted using a structured questionnaire ranging from 2 to 5 per focus group. Discussions were recorded, transcribed, and analyzed by two investigators following content analysis. Emerging themes were consensus of research team. Three main themes emerged from the focus group data analysis with subcategories: kid appeal (social, entertainment, and information, that reflected why they used the internet, why and what they liked from the HOT project website), healthy living (diet, exercise, sleeping, friendship, and studying), and living with and without diabetes (those who had relatives with diabetes or not). Subjects appreciated the design, information, and entertainment. They had specific suggestions for increased fun, options for social interaction, broader health coverage for topics, and more depth and scenarios for diabetes information for those with limited exposure to the condition.
\end{abstract}

Keywords: Health Education, Online Learning, Diabetes, Focus Groups

\section{Introduction}

As the prevalence of obesity and type 2 diabetes continues to increase in adolescents and youth, the number of interventions aiming to attenuate this situation has also increased. Adolescent interventions targeting healthy behaviors have been implemented in school and home environments. Evidence suggests that the most promising approaches for adolescents involve both families and schools and include a combination of physical activity and nutrition or nutrition alone. These interventions have demonstrated significant weight reduction effects, with theoretical framework providing significant impact (Waller, Eiser, Heller, Knowles, \& Price, 2005; Katz, O’Connell, Yeh, Nawaz, Njike, \& Anderson et al., 2005). Interventions integrating lessons about nutrition, physical activity, and reduction in screen time into the standard curriculum have a more profound effect than those outside of the school day that do not address this content (Gortmaker, Cheung, Peterson, Chomitz, Cradle, \& Dart et al., 2006; Mo-suwan, Pongprapai, Junjana, Puetpaiboon, 1998; Burke, Thompson, Taggart, Spickett, Beilin, \& Vandongen et al.,1998).

However, researchers have also used interactive learning, such as computer and video games, as a means of enhancing learning and fostering prevention. Proponents argue that computer games promote active learning and can enhance understanding of complex topics, while others believe computer games do not enhance learning and may create distractions (Ke, 2008). A recent literature review of computer and video games in health and physical education concluded that although conclusive evidence may be lacking, online health education features can be motivating and engaging (Papastergiou, 2009). In addition, it is estimated that teens in the United States (US) spend more than two hours a day online (Hasker \& Somosi, 2004), visiting such websites as MySpace, Facebook, and
Twitter; the top three in social networking sites, with over two billion monthly visits collectively (Kazeniac, 2009; Wang, 2010).

Given findings from previous interventions and the rapidly changing dynamic of the US demographics, this study used innovative technology to develop a prototype website focused on increasing diabetes and overweight awareness (Healthy Outcomes for Teens: HOT Project). The purpose of this study was to use focus groups to stimulate evaluation of the HOT Project website as a way to enhance sustainability and usability by the target audience.

\section{The Healthy Outcomes for Teens Project}

The HOT project website included content specific to 14 - 17 year olds with type 2 diabetes or at risk for type 2 diabetes, focused on skills and knowledge assessment, an overview of diabetes and food, relationship between diabetes and food, physical activity and weight management, and eating for target blood glucose levels organized in five modules (Castelli, Goss, Scherer, \& Chapman-Novakofski, 2011). The website was adapted from a previously effective website targeting adults which was developed in 2006 (Herrejon, Hartke, Scherer, \& Chapman-Novakofski, 2009). Similar to other healthy eating and physical activity online programs (Thompson, Baranowski, Cullen, \& Baranowski, 2007), the HOT Project was framed in Social Cognitive Theory (Bandura, 1986).

An interactive, participatory design was used so that sustainability and usability could be maximized. A distributed interactive environment (DIL) which permitted self-regulation and exploration at their own pace was used to ensure effectiveness and efficiency in learning (Kubik, Lytle, \& Fulkerson, 2005; Ott, Rosenburger, Woodcox, \& McBride, 2009). This non-linear design allowed individuals to revisit information based upon interest and need. We developed a teen council to assist in the design, topic coverage, and interactivity (Castelli, Goss, Scherer, \& Chapman-Novakofski, 2011). 
Two versions of the website were created with exactly the same information except the site for the treatment group had interactive features (animated pictures, videos, games and voiceovers) while the control group had passive, non-interactive texts. A total of 165 middle school students participated in the program which was incorporated in the regular school day in the physical education or health class, or in an after-school program (Castelli, Goss, Scherer, \& Chapman-Novakofski, 2011). The subjects were recruited from three middle schools, housed in different school districts of a Midwest county.

\section{Focus Groups}

Focus groups have been used successfully with the adolescent population to obtain qualitative information from relatively homogenous populations about attitudes, perceptions and opinions that can influence their behavior. Furthermore, focus groups also give the opportunity for exchange of ideas among the participants, to assess the degree of consensus and diversity of opinion, and to promote responses with depth and complex- ity (Weinger, O’Donnell, \& Ritholz, 2001). Focus groups are conducted using a general format of open-ended questions and the data are analyzed qualitatively to determine appropriate codes, themes and patterns (Ott et al., 2009; Weinger et al., 2001; Krueger, 1994).

\section{Methods}

The focus group interviews began with broad topics, progressing to more focused questions concerning which parts of the intervention they believed might be most compelling or appealing (Krueger, 1994). The script was developed by the research team and was field-tested for flow and clarity of the discussion questions. The University Institutional Review Board approved the protocol, and parental consent and child assent was obtained. Subjects were recruited from three school districts that participated in the HOT project and were in the treatment group $(n=101)$. Subjects $(n=42)$ participated in the focus groups in the last session of the HOT project. Twelve focus groups were conducted with 2 to 5 students in quiet private small rooms near the computer labs in the schools. Topic saturation indicated enough subjects had participated to provide robust findings.

Debriefing of moderator and co-moderator occurred immediately after the focus group to capture first impressions, and then highlight and contrast findings from earlier focus groups. These discussions were collected in formal observational notes as well as the fidelity-to-treatment logs. Additionally, each researcher recorded any unique demographics (i.e., gender, race) and situational events that may have taken place during the focus groups. The interview sessions took an average of 45 - 60 minutes. The focus group interviews were audio-taped and then transcribed verbatim.

\section{Data Analysis}

Specifically, the focus group data were analyzed using content analysis, which involves identifying coherent and important examples, themes and patterns in the data (Patton, 1987). First, these data were analyzed inductively, without regard to theory, by coding discrete statements and identifying patterns and themes, according to inductive category development methods (Mayring, 2000). Two researchers analyzed the transcribed focus group data separately to develop a list of keywords and codes. Independent summaries of the codes and patterns were presented in group debrief to audit the results. During the debrief, two analysts met with one principal investigator to arrive at a consensus for the final summary and to achieve greater than $85 \%$ agreement on the coding of the discrete statements. From the codes and frequency counts three overarching themes emerged.

A negative case analysis was conducted to ensure that all ideas had been accounted within the act of coding (Lincoln \& Guba, 1985). Negative cases were single or a collection of discrete statements that did not fall within the established defined codes. In this study, one negative case appeared suggesting that participants with relatives may have better insight into the prevention and treatment of diabetes. Given the potential effects of this finding, these data were again analyzed to determine if there was a difference in the responses of participants who had relatives with diabetes as compared to those without known relatives having diabetes for four questions. The four questions were frequency of Internet use, defining healthy outcome, defining diabetes, and recommendations for improving the website.

The second phase of analyses used deductive reasoning in that frequency counts and qualitative data, analyzed in a previous study (Castelli, Goss, Scherer, \& Chapman-Novakofski, 2011), were used to confirm the trustworthiness of the codes, patterns and themes in the present study. In this phase, the codes were compared holistically with the quantitative data of code frequency counts, knowledge test scores, risk for diabetes, and website hit counts, because themes should be identified before, during, and after the data collection (Denzin \& Lincoln, 1998). Further, the patterns and themes were reexamined from a theoretical perspective for consistencies.

\section{Results}

All subjects had access to the Internet, with more than 50\% using it daily, up to two hours per day. There were no substantial differences between genders or across schools in use, both in frequency and time. The results indicated that the Internet appeared to be an extension of daily living utilized for communication and information access.

When asked about defining healthy outcomes or diabetes, the subjects gave responses in the categories of diet, physical activity, studying, sleeping, and friendship. The diet category had the most varied responses and included answers such as healthy eating in general, eating fruits and vegetables, eating in moderation, no junk food and eating less meat. The participants expressed interest in learning more information about healthy living, diabetes and varied topics such as leukemia. Subjects also recommended adding more games, videos, pictures, music, social interaction features, voiceovers and cartoons, and less reading and easy vocabulary. The students thought the use of humor on such a serious topic would be valuable to gain and maintain attention.

The secondary analysis for identifying differences in responses from those with or without diabetes family histories indicated one difference. Subjects with family history of diabetes $(n=22)$ were more likely to comment on sugar level or sugar intake. Therefore, experience with a diabetic family member only minimally affected these findings.

Three main themes emerged from the focus group data analysis: kid appeal, healthy living, and living with and without diabetes.

Three main themes emerged from the focus group data analysis: kid appeal, healthy living, and living with and without 
diabetes,

\section{Kid Appeal}

The kid appeal theme was composed of three categories, namely social, entertainment, and information. These three categories were representative of the reasons these students used the internet, why and what they liked from the HOT project website, and what recommendations they gave to make the website better.

Social. MySpace was by far the favorite website for these subjects, with facebook being the third most favorite. These two websites fall in the social networking category. Other favorite websites were you tube, yahoo, games, and music websites for entertainment. The subjects recommended adding some social interaction features on the website such as having their own home page, username and password; getting in touch with people who have diabetes; chatting with friends who are also participating in the HOT project; and allowing people to choose what's on the page.

Entertainment. Games were the favorite part of the HOT project followed by videos and pictures. Among the games, jeopardy was the most popular and some subjects also mentioned liking blast off, foods on a plate, and word search. In addition to entertainment from the website, the students also liked the information presented, surveys, and design of the web page. Subjects want to make the website more entertaining by adding more games, music, pictures, videos, and funny text.

Information. The diabetes, exercise and health information presented on the website was well perceived by the subjects and they recommended adding information about how to get active, more examples of people having diabetes, translating to other languages, more voiceovers, easier vocabulary, and making websites with information on how the brain works and cancer/ leukemia.

\section{Healthy Living}

The second prominent theme in the focus group data was 'healthy living'. Their responses fell in five categories namely diet, exercise, sleeping, friendship, and studying. Most of the answers were in the diet category and included responses such as eating healthy foods, eating fruits and vegetables, following a diet, eating in moderation, not eating junk food, and eating good nutrition. The exercise category included exercising, playing sports, and staying fit.

\section{Living with and without Diabetes}

The third theme emerging from the focus group analysis was 'living with and without diabetes'. The responses of subjects who had relatives with diabetes to diabetes related questions were more knowledgeable. Twenty-two subjects had family members who had diabetes. The subjects' responses to defining diabetes included “can't eat a lot of sugar, blood glucose level low/high, insulin low/get shots, a sickness/disease, causes frequent urination, high blood pressure causes diabetes, and kidneys might die". Subjects who had family members with diabetes were three times more likely to make a comment related to sugar intake or insulin level.

\section{Discussion}

Despite developing a highly interactive website, the participants requested that there be more interactivity and social interaction. These concepts reflect the "Toy" and "Telephone" attributes of a 5-T model (Tool, Toy, Telephone, Territory, and
Treasure of Information) used to describe elementary school students in Taiwan's attitude toward the internet (Chou, $\mathrm{Yu}$, Chen, \& Wu, 2009). However, if the researchers were to accommodate this request, it is unclear at what point there would be too much interactivity. Some researchers have suggested that too much interaction can be a distraction to learning and therefore future studies should examine the effects of hyper-interactivity on learning (Ke, 2008). Further study with this population is warranted.

A study by Schiffman et al. on Internet use among adolescent and young adults with cancer supports the findings of our focus groups. Most subjects reported Internet use daily and for an average of two hours (Schiffman, Csongradi, \& Suzuki, 2008). They identified 21 desired features on a health website to make it more appealing to browse. Most of them fell in the three categories, social, information and entertainment; the same themes were also identified in the HOT project study, and may reflect the Tool/Treasure of Information, Telephone/Territory, and Toy perspectives of the $5 \mathrm{~T}$ model (Chou et al., 2009).

Like older adults, Internet use for seeking health information is becoming popular in the adolescent population, thus making Internet a well-suited medium to provide a variety of resources (Schiffman et al., 2008). Brown, Teufel, \& Birch, 2006 suggested adolescents learn the most about health from school and the Internet. Similar to our study, a project involving children aged 7 to 8 concluded that even young students valued fun in educational software (Sim, MacFarlane, \& Read, 2006). However, learning was not always correlated with fun and usability was important. Consequently, to enhance the impact of healthrelated websites, social and entertainment features must be incorporated with learning and usability remaining as the primary focus.

Most but not all responses concerning healthy living reflected content provided in the online modules. Indeed, most interventions for this age group that target obesity prevention focus on healthy eating and physical activity (Weight Realities Division of the Society for Nutrition Education, 2003; Zenzen \& Kridli, 2009). Sleeping, friendship, and studying were also mentioned. Some studies report less sleep to be associated with higher BMI in children (Hitze, Bosy-Westphal, Bielfeldt, Settler, Plachta-Danielzik, \& Pfeuffer, 2009). Although the major determinant of sleep in this study conducted by Hitze et al. was age, physical activity was not a major determinant. In other studies as well, short sleep is a modifiable predictor of overweight and obesity in adolescents (Bibiloni, Martinez, Llull, Juarez, Pons, \& Tur, 2010). Interestingly, one study of sleep and children found fatigue equal to that of cancer patients in obese but not normal weight children (Varni, Limbers, Bryant, \& Wilson, 2010). These findings suggest perhaps sleep could be included in healthy outcomes programs for this age group.

Research has found that peers or friends can influence body weight both positively and negatively. That is, friends can provide support or pressure for healthy behaviors, or conversely unhealthy behaviors (Lytle, Murray, Perry, Story, Birnbaum, \& Kubik, et al., 2004; Eisenberg, Neumark-Sztainer, Story, \& Perry, 2005). One study also reported that children with higher body mass indices tended to associate with similarly weighted peers, and this clustering also seemed to have gender influences as well, with similar genders being most sensitive to each other (Renna, Grafova, \& Thakur, 2008). The mentioning of friends as part of a healthy outcome coupled with the request for more social interaction suggests that friends, peers, and positive guiding of this influence may be very important to successful outcomes. 
Those subjects who had relatives with diabetes more frequently reported diabetes-related knowledge about treatment (care) but not necessarily prevention. The interpretation of family history of disease in adults has been explored to a limited degree. In one study, the adults had little worry that their children would develop a chronic disease although they themselves felt at risk (Walter \& Emory, 2005). Unfortunately, there is a paucity of studies concerning children's perception of risk for chronic disease for which they have a family history. Future research could explore this within a social learning context.

The limitation of these findings must be noted. Because the focus group participants were recruited from the HOT project intervention study, there is concern of limited transferability and the possibility of selection bias. However, the focus groups sessions provided an opportunity for in-depth discussion of questions and reaction to comments made by other participants.

\section{Conclusion}

These results confirmed the researchers' hypothesis that "kid appeal" would make the program attractive to this audience. However, the teens also wanted more information and social interaction. Future studies should address other aspects of healthy outcomes, particularly sleep and academics. Finally, how adolescents perceive the impact of family history for disease needs to be more fully evaluated to successfully design effective education.

\section{Acknowledgements}

This project was supported by funding from the American Dietetic Association Foundation, the National Soybean Research Laboratory, University of Illinois Extension Service, and the Illinois Soybean Association.

\section{References}

Bandura, A. (1986). Social foundations of thought and action: A social cognitive theory. Englewood Cliffs, NJ: Prentice Hall.

Bibiloni, M. D., Martinez, E., Llull, R., Juarez, M. D., Pons, A., \& Tur, J. A. (2010). Prevalence and risk factors for obesity in Balearic Islands adolescents. British Journal of Nutrition, 103, 99-106. doi:10.1017/S000711450999136X

Brown, S. L., Teufel, J. A., \& Birch, D. A. (2007). Early adolescents perceptions of health and health literacy. Journal of School Health, 77, 7-15. doi:10.1111/j.1746-1561.2007.00156.x

Burke, V., Thompson, C., Taggart, A. C., Spickett, E. E., Beilin, L. J., Vandongen, R., Milligan, R. A., \& Dunbar, D. L. (1998). A controlled trial of health promotion programs in 11-year-olds using physical activity "enrichment" for higher risk children. Journal of Pediatrics, 132, 840-848. doi:10.1016/S0022-3476(98)70315-4

Castelli, D., Goss, D., Scherer, J. A., \& Chapman-Novakofski, K. (2011). Healthy outcomes for teens (HOT) project: Diabetes prevention through distributed interactive learning. Diabetes Technology \& Therapeutics, 13. doi:10.1089/dia.2010.0125

Chou, C., Yu, S., Chen, C., \& Wu, H. (2009). Tool, toy, telephone, territory or treasure of information: Elementary school students' attitudes toward the internet. Computers \& Education, 53, 308-316. doi:10.1016/j.compedu.2009.02.003

Denzin, N. K., \& Lincoln, Y. S. (1998). Strategies of qualitative inquiry. London: Sage Publications.

Eisenberg, M. E., Neumark-Sztainer, D., Story, M., \& Perry, C. (2005). The role of social norms and friends' influences on unhealthy weightcontrol behaviors among adolescent girls. Social Science \& Medicine, 60, 1165-1173. doi:10.1016/j.socscimed.2004.06.055
Gortmaker, S. L., Cheung, L. W., Peterson, K. E., Chomitz, G., Cradle, J. H., Dart, H., et al. (1999). Impact of a school-based interdisciplinary intervention on diet and physical activity among urban primary school children: Eat well and keep moving. Archives of Pediatrics \& Adolescent Medicine, 153, 975-983.

Hasker, S. J., \& Somosi, A. (2004). Marketing to teens online. URL (last checked September 2011) http://www.mckinseyquarterly.com/Marketing/Digital_Marketing/M arketing_to_teens_online_1471

Herrejon, K., Hartke, J. L., Scherer, J., \& Chapman-Novakofski, K. (2009). The creation and impact evaluation of your guide to diet and diabetes, an interactive web-based diabetes tutorial. Diabetes Technology \& Therapeutics, 11, 1-9. doi:10.1089/dia.2008.0043

Hitze, B., Bosy-Westphal, A., Bielfeldt, F., Settler, U., Plachta-Danielzik, S., Pfeuffer, M., et al. (2009). Determinants and impact of sleep duration in children and adolescents: Data of the Kiel obesity prevention study. European Journal of Clinical Nutrition, 63, 739-746. doi:10.1038/ejcn.2008.41

Katz, D. L., O’Connell, M., Yeh, M. C., Nawaz, H., Njike, V., Anderson, L. M., et al. (2005). Task Force on Community Preventive Services. Public health strategies for preventing and controlling overweight and obesity in school and worksite settings: A report on recommendations of the Task Force on Community Preventive Services. MMWR Recommendations and Reports, 54, 1-12.

Kazeniac, A. (2009). Social networks: Facebook takes over top spot. Twitter Climbs. URL (last checked September 2011)

http://blog.compete.com/2009/02/09/facebook-myspace-twitter-socia l-network

Ke, F. (2008). A case study of computer gaming for math: Engaged learning from gameplay? Computers \& Education, 51, 1609-1620. doi:10.1016/j.compedu.2008.03.003

Krueger, R. A. (1994). Focus groups: A practical guide for applied research (2nd ed.). Thousand Oaks, CA: Sage Publications.

Kubik, M. Y., Lytle, L., \& Fulkerson, J. A. (2005). Fruits, vegetables, and football: Findings from focus groups with alternative high school students regarding eating and physical activity. Journal of Adolescent Health, 36, 494-500. doi:10.1016/j.jadohealth.2004.05.010

Lincoln, Y. S., \& Guba, E. G. (1985). Naturalistic inquiry. Newbury Park, CA: Sage Publications.

Lytle, L. A., Murray, D. M., Perry, C. L., Story, M., Birnbaum, A. S., Kubik, M. Y., et al. (2004). School-based approaches to affect adolescents' diets: Results from the TEENS study. Health Education \& Behavior, 31, 270-287. doi:10.1177/1090198103260635

Mayring, P. (2000). Qualitative content analysis. Forum: Qualitative Social Research, 1. URL (last checked September 2011) http://www.qualitative-research.net/fqs-texte/2-00/02-00mayring-e.htm

Mo-suwan, L., Pongprapai, S., Junjana, C., \& Puetpaiboon, A. (1998). Effects of a controlled trial of a school-based exercise program on the obesity indexes of preschool children. American Journal of Clinical Nutrition, 68, 1006-1011.

Ott, M. A., Rosenburger, J. G., Woodcox, S. G., \& McBride, K. R. (2009). Youth perspective on health and wellness: A focus group study. Journal of Adolescent Health, 44, S41-S42. doi:10.1016/j.jadohealth.2008.10.116

Papastergiou, M. (2009). Digital game-based learning in high school computer science education: Impact on educational effectiveness and student motivation. Computers \& Education, 52, 1-12. doi:10.1016/j.compedu.2008.06.004

Patton, Q. M. (1987). How to use qualitative methods in evaluation. Newsbury Park, London, New Dehli: Sage Publications.

Renna, F., Grafova, I. B., \& Thakur, N. (2008). The effect of friends on adolescent body weight. Economics \& Human Biology, 6, 377-387. doi:10.1016/j.ehb.2008.06.005

Schiffman, J. D., Csongradi, E., \& Suzuki, L. K. (2008). Internet use among adolescent and young adults (AYA) with cancer. Pediatric Blood \& Cancer, 51, 410-415. doi:10.1002/pbc.21616

Sim, G., MacFarlane, S., \& Read, J. (2006). All work and no play: Measuring fun, usability, and learning in software for children. Computers \& Education, 46, 235-248. doi:10.1016/j.compedu.2005.11.021

Thompson, D., Baranowski, J., Cullen, K., \& Baranowski, T. (2007). Development of a theory-based internet program promoting maintenance of diet and physical activity change to 8-year-old African Am- 
erican girls. Computers \& Education, 48, 446-459. doi:10.1016/j.compedu.2005.02.005

Waller, H., Eiser, C., Heller, S., Knowles, J., \& Price, K. (2005). Adolescents' and their parents' views on the acceptability and design of a new diabetes education programme: A focus group analysis. Child: Care, Health and Development, 31, 283-289.

Walter, F. M., \& Emory, J. E. (2005). Coming down the line: Patients' understanding of their family history of common chronic disease. Annals of Family Medicine, 3, 405-414. doi:10.1370/afm.368

Wang, B. (2010). Survival and competition among social networking websites: A research commentary on "critical mass and willingness to pay for social networks" by J. Christopher Westland. Electronic Commerce Research and Applications, 9, 20-22. doi:10.1016/j.elerap.2009.08.002
Weight Realities Division of the Society for Nutrition Education. (2003). Guidelines for childhood obesity programs: Promoting healthy weight in children. Journal of Nutrition Education and Behavior, 35, 1-4. doi:10.1016/S1499-4046(06)60318-7

Weinger, K., O’Donnell, K. A., \& Ritholz, M. D. (2001). Adolescent views of diabetes-related parent conflict and support: A focus group analysis. Journal of Adolescent Health, 29, 330-336.

Varni, J. W., Limbers, C. A., Bryant, W. P., \& Wilson, D. P. (2010). The PedsQL multidimensional fatigue scale in pediatric obesity: Feasibility, reliability and validity. International Journal of Pediatric Obesity, 5, 34-42. doi:10.3109/17477160903111706

Zenzen, W., \& Kridli, S. (2009). Integrative review of school-based childhood obesity prevention programs. Journal of Pediatric Health Care, 23, 242-258. doi:10.1016/j.pedhc.2008.04.008 